\title{
Countercurrent chromatographic fractionation followed by gas chromatography/mass spectrometry identification of alkylresorcinols in rye
}

\author{
Tim Hammerschick ${ }^{1} \cdot$ Tim Wagner $^{1} \cdot$ Walter Vetter $^{1}$
}

Received: 18 August 2020 / Revised: 24 September 2020 / Accepted: 29 September 2020 / Published online: 10 October 2020 (C) The Author(s) 2020

\begin{abstract}
Alkylresorcinols (5-alkyl-1,3-dihydroxybenzenes, ARs) are bioactive phenolic lipid compounds which are particularly abundant in rye and partly other cereals. In this study on ARs, whole rye grain extracts were gained with cyclohexane/ethyl acetate (46/54, $\mathrm{w} / \mathrm{w})$. Silylated extracts were used to develop a gas chromatography with mass spectrometry method in the selected ion monitoring mode (GC/MS-SIM) for the sensitive detection of conventional ARs along with keto-substituted (oxo-AR) and ring-methylated ARs (mAR) with 5-alkyl chain lengths of 14 to 27 carbon atoms and 0 to 4 double bonds in one run. Analysis was performed by countercurrent chromatographic (CCC) fractionation using the solvent system $n$-hexane/ethyl acetate/methanol/water (9/1/9/1, v/v/v/v). Subsequent GC/MS-(SIM) analysis of 80 silylated CCC fractions enabled the detection of 74 ARs in the sample. The CCC elution of the ARs followed the equivalent chain length (ECL) rule in which one double bond compensated the effect of two (additional) carbon atoms. Novel or rarely reported ARs were detected in virtually all classes, i.e. saturated AR (AR14:0), even-numbered monounsaturated AR isomers (AR16:1-AR26:1), triunsaturated ARs (AR25:3), oxoARs (AR17:0 oxo, AR19:1 oxo, AR21:2 oxo, AR23:2 oxo) and odd-numbered methyl-ARs (mAR15:0-mAR23:0). Positions of the double bonds of monounsaturated ARs and oxo-ARs were determined with the help of dimethyl disulfide (DMDS) derivatives.
\end{abstract}

Keywords Alkylresorcinols $\cdot$ Rye $\cdot$ Countercurrent chromatography $\cdot$ Gas chromatography $\cdot$ Mass spectrometry

\section{Introduction}

Alkylresorcinols (ARs) are amphiphilic 1,3-dihydroxybenzene (resorcinol) derivatives characterized by a hydrocarbon chain on C-5 of the resorcinol backbone (Fig. 1) [1]. ARs are bioactive molecules, which may display favourable antioxidative, anticancerogenic, antimicrobial and antiparasitic effects [2, 3]. Also, inhibition of some metabolic enzymes has been observed in in vitro assays [4].

The most relevant dietary sources of ARs are rye and other members of the Gramineae family (especially wheat and

Electronic supplementary material The online version of this article (https://doi.org/10.1007/s00216-020-02980-3) contains supplementary material, which is available to authorized users.

Walter Vetter

walter.vetter@uni-hohenheim.de

1 Department of Food Chemistry (170b), Institute of Food Chemistry, University of Hohenheim, 70599 Stuttgart, Germany triticale), in which ARs may contribute with more than $500 \mu \mathrm{g}$ to $1 \mathrm{~g}$ of the fresh weight [1]. Specifically, highest AR amounts are found in the outer cuticula [5]. Rye is not only the richest source of ARs but also known for a high variety of AR structures [1]. In the following, these will be discussed by means of short terms of the "ARn:m" type, in which $n$ represents the length of the hydrocarbon chain on C-5 and $m$ the number of double bonds.

High-performance liquid chromatography with tandem mass spectrometry (HPLC/MSMS) [6] and gas chromatography with mass spectrometry (GC/MS) analyses [7] showed that $\sim 85 \%$ of the ARs in rye feature a saturated alkyl chain (ARn:0) [8]. The most relevant representatives are odd-numbered (AR17:0-AR25:0) along with low shares of AR15:0 and AR27:0 and even-numbered homologues (AR16:0-AR24:0) $[6,9]$. The remaining share of $\sim 15 \%$ constitutes mainly of mono- (ARn:1), di- (ARn:2) and tri- (ARn:3) unsaturated hydrocarbon chains (alkenylresorcinols). In addition, hydroxyl (ARn:1-OH) and keto (ARn:0 oxo) groups can be present as substituents on the alkyl chain $[6,7,10]$. 


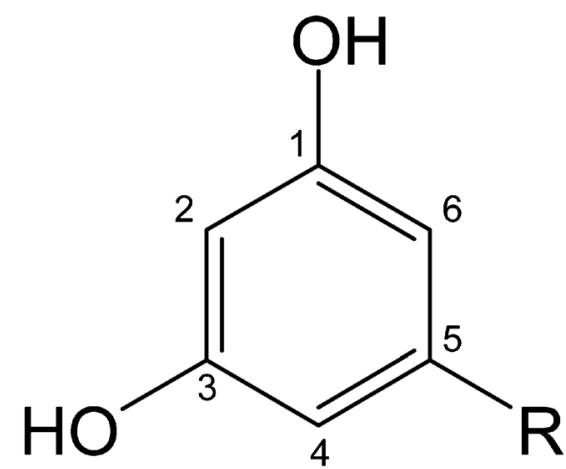

Fig. 1 Chemical structure of 5-n-alkylresorcinol with $R=$ (un)saturated hydrocarbon chain (with keto- or hydroxyl-group)

The goal of our study was to expand the array of methods for studying AR profiles by means of countercurrent chromatography $(\mathrm{CCC})$. This preparative all-liquid chromatography technique is frequently used in the field of natural and synthetic products $[11,12]$. In CCC, the separation is based on the different distribution of the analytes in two immiscible liquid phases, with one being used as stationary and the other one as mobile phase [11]. ARs were not studied by CCC but Marchal et al. developed a strategy for the optimization of the injection step using the related centrifugal partition chromatography (CPC) technique [13]. In that paper, one example included the purification of major ARs with the solvent system $n$-heptane/methanol but without presenting details of the separation [13]. Moreover, a symposium abstract indicated the analysis of an AR extract by CPC [14]. The focus of the present work was to select a suitable solvent system which provides partition coefficients ( $K$ values) of ARs in the sweet spot range of $0.4<K<2.5$ [15], followed by its use for the analysis of major and minor ARs in rye. For this purpose, small CCC fractions were collected and analysed after silylation by GC/MS measurements. This approach was found to enable the detection of more compounds than without implementing CCC [16]. For example, 430 fatty acid methyl esters were detected in a transesterified butter sample [17] and $>170$ tocochromanol artefacts in a vitamin E capsule [18]. In addition, a GC/MS method in the selected ion monitoring (SIM) mode was developed for the detection of minor ARs. The position of the double bond was determined if unknown or confirmed if known by means of dimethyl disulfide (DMDS) derivatives similarly to approaches used for fatty acids and other compounds with double bonds $[19,20]$.

\section{Materials and methods}

\section{Rye sample and chemicals}

Several 1-kg packages of whole rye grains from German organic cultivation were bought in a retail shop in Stuttgart, Germany.
Acetic anhydride (> 99\%), anhydrous benzotrifluoride (BTF, > $99 \%$ ), dimethyl disulfide (>99\%), ethyl acetate (>99\%), pyridine ( $>99 \%$, distilled before use) and silica gel 60 were from Sigma-Aldrich (Steinheim, Germany) while methanol, $n$-hexane (both HPLC grade), cyclohexane (>99\%) and toluene (>99\%) were from Th. Geyer (Renningen, Germany). Iodine (>99.5\%) was from Fluka (Taufkirchen, Germany) and sodium thiosulfate (>99\%) was from Carl Roth (Karlsruhe, Germany). The azeotropic mixture cyclohexane/ethyl acetate (CE) (46:54, $\mathrm{w} / \mathrm{w})$ was obtained by distillation of mixture $(1: 1, \mathrm{v} / \mathrm{v})$. N,Obis(trimethylsilyl)trifluoroacetamide (BSTFA) and trimethylchlorosilane (TMCS), 99:1 (v/v), was from Macherey Nagel (Düren, Germany). The internal standard $5 \alpha$-cholestane (>98\%) was from Acros Organics (Geel, Belgium) and docosanoic acid methyl ester (22:0-ME) was prepared by the methylation protocol of Wendlinger et al. [21] using $40 \mathrm{mg}$ 22:0 (Fluka, Taufkirchen, Germany) and $4 \mathrm{~mL}$ methanol. Helium and hydrogen (5.0 quality) were from Westfalen (Münster, Germany). Demineralized water was produced in-house.

\section{Extraction of alkylresorcinols from the rye sample}

Different solvents including alkanes ( $n$-hexane and cyclohexane) and ethyl acetate were suggested for the extraction of different groups of ARs [22]. Own experience with the azeotropic mixture of cyclohexane and ethyl acetate [23] indicated that this solvent mixture could take advantage of the reported positive properties of its individual parts. Accordingly, whole rye grains ( $60 \mathrm{~g}$ for column chromatography, $700 \mathrm{~g}$ for $\mathrm{CCC}$ ) were placed in a $250-\mathrm{mL}$ conical flask or in a 2.5-L brown glass bottle, respectively. The azeotropic $\mathrm{CE}$ mixture $(100 \mathrm{~mL}$ for column chromatography, $1 \mathrm{~L}$ for $\mathrm{CCC}$ ) was added and ARs were cold extracted with occasional shaking for $24 \mathrm{~h}$ at room temperature. The resulting raw extracts were passed through a folded filter into a second $250-\mathrm{mL}$ or 1-L flask. The solvent was evaporated by rotary evaporation and the residue was transferred with $\mathrm{CE}$ into a pre-weighed 4-mL vial. The weight of the vial was determined after drying using a gentle stream of nitrogen at $40{ }^{\circ} \mathrm{C}$.

\section{Preparation of trimethylsilyl ether derivatives of alkylresorcinols}

Silylation of aliquots of samples and fractions was performed in 1.5-mL vials according to Hammann et al. [24]. The solvent was evaporated under nitrogen at $40{ }^{\circ} \mathrm{C}$. To the dry residue, $50 \mu \mathrm{L}$ silylating agents (BSTFA/TMCS, 99:1, v/v) and $25 \mu \mathrm{L}$ pyridine were added and the closed vial was carefully shaken and then heated for $30 \mathrm{~min}$ to $60{ }^{\circ} \mathrm{C}$. Afterwards, the excess reagent was evaporated under a gentle stream of nitrogen at $40{ }^{\circ} \mathrm{C}$ and the residue was re-dissolved in $1 \mathrm{~mL}$ internal standard solution, that is $5 \mu \mathrm{g} / \mathrm{mL} 5 \alpha$-cholestane in $n$-hexane (in the case of the rye extract, all solid phase extraction (SPE) 
fractions $1-3$, shake flask experiments and CCC fractions measured in full scan mode) or $5 \mu \mathrm{g} / \mathrm{mL} 22: 0$-ME in $n$-hexane (in the case of SPE fraction 4 and all CCC fractions and measured in GC/MS-SIM mode). These solutions were used for GC/MS measurements. Noteworthy, silylation takes place in both 1- and 3-positions of ARs (disilylated-ARs). However, for reasons of simplicity, the corresponding products will be listed simply as silylated ARs later on.

\section{Preparation of acetylated alkylresorcinol derivatives}

Aliquots $(\sim 0.1 \mathrm{mg})$ of selected CCC fractions $(6,7,10,16$, $24)$ were placed in a $1.5-\mathrm{mL}$ vial and supplemented with $50 \mu \mathrm{L}$ acetic anhydride and $100 \mu \mathrm{L}$ pyridine [18]. The sealed vial was heated to $60{ }^{\circ} \mathrm{C}$ for $2 \mathrm{~h}$ and at the end of the reaction, the solvent was removed by a gentle stream of nitrogen at $40{ }^{\circ} \mathrm{C}$. The residue was dissolved in $1 \mathrm{~mL}$ internal standard solution $(5 \mu \mathrm{g} / \mathrm{mL} 5 \alpha$-cholestane in $n$-hexane or $5 \mu \mathrm{g} / \mathrm{mL}$ 22:0-ME in $n$-hexane).

\section{Preparation of dimethyl disulfide adducts of alkylresorcinols}

Samples were prepared according to the protocol of Buser et al. [20] with slight modifications. An aliquot $(\sim 200-\mu \mathrm{g}$ sample of selected CCC fractions 6, 7, 10, 14, 16, 22, 24, 38 and 59, respectively) was dissolved in $50 \mu \mathrm{L} n$-hexane in a 2 -mL vial. After addition of $100 \mu \mathrm{L}$ DMDS and $10 \mu \mathrm{L}$ iodine solution (6\% iodine in diethyl ether), the vial was sealed with a cap and heated to $60{ }^{\circ} \mathrm{C}$ for $24 \mathrm{~h} \mathrm{[20].} \mathrm{After} \mathrm{cooling,} 1 \mathrm{~mL}$ aqueous sodium thiosulfate (5\%) and $500 \mu \mathrm{L} n$-hexane were added. The vial was shaken and after phase separation, $300 \mu \mathrm{L}$ of the upper organic phase was carefully transferred into a new vial. The solvent was evaporated and the residue was silylated and analysed by GC/MS.

\section{Solid phase extraction in a glass column}

Lipid classes were separated by SPE in duplicate according to Hammann et al. [25]. Five grams of deactivated silica gel $(20 \%$ water, $\mathrm{w} / \mathrm{w})$ was placed in a glass column $(1-\mathrm{cm}$ inner diameter). After conditioning of the column with $30 \mathrm{~mL} \mathrm{n}$ hexane, the AR extract ( $100 \mathrm{mg}$ dissolved in $2 \mathrm{~mL} n$-hexane) was placed onto the column. SPE fraction 1 containing hydrocarbons was eluted with $30 \mathrm{~mL} n$-hexane. Steryl esters (SPE fraction 2) were eluted with $40 \mathrm{~mL} n$-hexane/ethyl acetate $(99: 1, \mathrm{v} / \mathrm{v})$. SPE fraction 3 (triacylglycerols) was obtained with $50 \mathrm{~mL} n$-hexane/ethyl acetate $(95: 5, \mathrm{v} / \mathrm{v})$. Finally, ARs, free fatty acids, sterols and other alcohols were gained by flushing the column with $40 \mathrm{~mL}$ ethyl acetate (SPE fraction 4). Each SPE fraction was collected in a separate $100-\mathrm{mL}$ pear-shaped flask and the solvent was evaporated to dryness by rotary evaporation. The residues were transferred with $n$ - hexane into pre-weighed vials, the solvent was evaporated under a gentle stream of nitrogen at $40{ }^{\circ} \mathrm{C}$ and the vials were weighed again. An aliquot of $100 \mu \mathrm{g}$ of each SPE fraction was silylated and analysed by GC/MS.

\section{Determination of $K_{\mathrm{U} / \mathrm{L}}$ values for alkylresorcinols}

To find a suitable solvent system for the CCC separation, shake flask tests according to Ito [11] were performed with the setup of Schröder et al. [26] except the use of slightly larger sample vials. About $200 \mu \mathrm{g}$ of the rye extract eluting into SPE fraction 4 was placed into an $8-\mathrm{mL}$ vial and $1 \mathrm{~mL}$ of the lower and upper phase of the pre-equilibrated solvent systems was added. After vigorous shaking and phase separation, aliquots of $500 \mu \mathrm{L}$ were transferred from both phases into distinct $1.5-\mathrm{mL}$ vials. After removing the solvents from both vials by a gentle stream of nitrogen at $40{ }^{\circ} \mathrm{C}$, ARs were silylated as described above. Then, the solutions were evaporated again to dryness and made up with exactly $1 \mathrm{~mL} n$ hexane supplemented with $5 \mu \mathrm{g}$ of the internal standard $5 \alpha-$ cholestane. GC/MS peak areas of individual ARs were normalized by the peak area of the internal standard $5 \alpha$ cholestane in the respective solution. GC/MS measurements were carried out in triplicate and mean $K_{\mathrm{U} / \mathrm{L}}$ values were calculated from the corrected peak areas by dividing the peak areas of the substances in the upper phase by the complementary peak areas in the lower phase.

\section{Countercurrent chromatography}

CCC separations were performed with a Quickprep MK8 instrument (AECS London, UK) using the periphery recently described by Hammann et al. [24]. Two of the instrument's four coils, namely coil 2 in bobbin 1 and coil 3 in bobbin 2 (total volume $236 \mathrm{~mL}$ ), were selected for the separations. The rotor speed was set to the maximum value of $870 \mathrm{rpm}$. The temperature was maintained at $22{ }^{\circ} \mathrm{C}$ by external cooling. The effluent of the CCC centrifuge was continuously monitored at a wavelength of $210 \mathrm{~nm}$ with a flash 10 diode array detector (DAD; Ecom, Praha, Czech Republic) and fractions were collected using a Gilson 203 B fraction collector (Middleton, WI, USA).

The solvent system $n$-hexane/ethyl acetate/methanol/water $(9: 1: 9: 1, \mathrm{v} / \mathrm{v} / \mathrm{v} / \mathrm{v})$ was prepared in a $2.5-\mathrm{L}$ separation funnel. After vigorous shaking and an equilibration time of $1 \mathrm{~h}$, both phases were separated and degassed by ultrasonication. The selected coils were filled with upper (stationary) phase at $10 \mathrm{~mL} / \mathrm{min}$. Thereafter, the flow rate was reduced to $2 \mathrm{~mL} /$ min and rotation was started. In head-to-tail mode, the lower (mobile) phase was pumped into the two coils. After determination of the retention of the stationary phase $\left(S_{\mathrm{f}}=86 \%, 33-\mathrm{mL}\right.$ extruded stationary phase) by collecting the effluent in a graduated cylinder, $900 \mathrm{mg}$ of the rye extract, dissolved in $4.5 \mathrm{~mL}$ lower and $4.5 \mathrm{~mL}$ upper phase, was injected into the $\mathrm{CCC}$ 
system. After a delay of $30 \mathrm{~mL}, 80$ fractions of $7 \mathrm{~mL}$ each were collected from 30 to $590 \mathrm{~mL}$. CCC fractions were liberated from solvent by means of a rotational vacuum concentrator $(10 \mathrm{mbar}$, $\left.80^{\circ} \mathrm{C}, 1500 \mathrm{rpm}\right)(\mathrm{RVC} 2-33 \mathrm{IR}$, Martin Christ, Osterode am Harz, Germany). After determination of the sample weight, fractions were re-dissolved in $1 \mathrm{~mL}$ CE. Aliquots of each vial were silylated and analysed by GC/MS-SIM.

\section{Gas chromatography with mass spectrometry}

Silylated total lipid extracts, solid phase extraction fractions 1 to 3 as well as solutions with DMDS adducts and acetylated sample solutions were analysed on GC/MS system 1 (6890/5973 GC/MS system equipped with a cool-on-column inlet and a 7683 autosampler, Hewlett-Packard/Agilent, Waldbronn, Germany). Injections $(1 \mu \mathrm{L})$ were made onto a Zebron guard column with deactivated tubing ( $2 \mathrm{~m}, 0.53-\mathrm{mm}$ i.d., Phenomenex, Aschaffenburg, Germany) connected to a ZB-1HT capillary column (15 m, 0.25-mm i.d., 0.1- $\mu \mathrm{m}$ film thickness, Phenomenex, Aschaffenburg, Germany). Helium (5.0) was used as the carrier gas at a flow rate of $1.2 \mathrm{~mL} /$ min. The column oven was programmed according to Hammann et al. [18] but with a higher initial temperature: After $1 \mathrm{~min}$ at $100{ }^{\circ} \mathrm{C}$, the oven was heated at $10^{\circ} \mathrm{C} / \mathrm{min}$ to $250{ }^{\circ} \mathrm{C}$ (hold time $5 \mathrm{~min}$ ), then at $5{ }^{\circ} \mathrm{C} / \mathrm{min}$ to $300{ }^{\circ} \mathrm{C}$ and finally the temperature was raised at $30{ }^{\circ} \mathrm{C} / \mathrm{min}$ to $350{ }^{\circ} \mathrm{C}$ (hold time $10 \mathrm{~min})$. Transfer line $\left(320^{\circ} \mathrm{C}\right)$, ion source $\left(230{ }^{\circ} \mathrm{C}\right)$ and quadrupole $\left(150^{\circ} \mathrm{C}\right)$ were heated to the values shown in parentheses. After a solvent delay of $6 \mathrm{~min}$, data was recorded from $\mathrm{m} / \mathrm{z}, 50$ to 800 in GC/MS full scan mode.

Silylated CCC fractions and SPE fraction 4 (containing ARs) were analysed with GC/MS system 2 (a second 6890/ $5973 \mathrm{GC} / \mathrm{MS}$ system equipped with split/splitless injector (Hewlett-Packard/Agilent, Waldbronn, Germany). An MPS 2 autosampler (Gerstel, Mülheim, Germany) was used for splitless injections $(1 \mu \mathrm{L})$ into the injector port maintained at $250^{\circ} \mathrm{C}$. The carrier gas helium 5.0 with a constant flow rate of $1.0 \mathrm{~mL} / \mathrm{min}$ was transported through a Zebron guard column with deactivated tubing ( $2 \mathrm{~m}, 0.25-\mathrm{mm}$ i.d.) (Phenomenex, Aschaffenburg, Germany) followed by an Optima 5HT column (30 m, 0.25-mm i.d., 0.25- $\mu \mathrm{m}$ film thickness, Macherey Nagel, Düren, Germany). After $1 \mathrm{~min}$ at $55^{\circ} \mathrm{C}$, the GC oven was heated to $200^{\circ} \mathrm{C}$ with a ramp of $10^{\circ} \mathrm{C} / \mathrm{min}$ (no hold time), and finally the oven temperature was raised at $5{ }^{\circ} \mathrm{C} / \mathrm{min}$ to $320^{\circ} \mathrm{C}$ (15-min hold time). Temperatures of the transfer line, ion source and quadrupole were set at $280{ }^{\circ} \mathrm{C}, 230^{\circ} \mathrm{C}$ and $150{ }^{\circ} \mathrm{C}$, respectively. In the full scan mode, $\mathrm{m} / \mathrm{z}, 50-650$ were measured over the total run time of 54.5 min after a solvent delay of $7 \mathrm{~min}$.

GC/MS-SIM measurements were applied to possible ARs with chain lengths of 14 to 27 carbon atoms and 0 to 4 double bonds (see Electronic Supplementary Material (ESM), Table S1). GC/MS analysis of silylated extracts allowed a secure identification of prominent ARs based on the distinct molecular ions [27] along with three additional diagnostic fragment ions. These are (i) the base peak at $m / z, 268$ (formed by McLafferty rearrangement of the resorcinol ring) along with (ii) the ditrimethylsilyloxy substituted tropylium ion at $\mathrm{m} / \mathrm{z}, 267$ (formed by benzyl cleavage) and (iii) $\mathrm{m} / \mathrm{z} 281$ (formed by cleavage between $\mathrm{C} 2$ and C3 in the alkyl chain) (ESM Fig. S1) [28, 29].

\section{Results and discussion}

\section{GC/MS analysis of rye grain extract}

Evaporation of the solvent after cold extraction of $700-\mathrm{g}$ whole rye grain for CCC separation yielded 2.54-g sample $(0.36 \%)$. GC/MS analysis of a silylated aliquot verified the predominance of odd-numbered ARs AR15:0-AR25:0 along with odd-numbered alkenylresorcinols AR17:1-AR21:1 (Fig. 2 and ESM Fig. S2). In addition, the silylated extract featured triacylglycerols as well as silylated $\beta$-sitosterol and campesterol (ESM Fig. S2) [8]. SPE fractionation of two 100$\mathrm{mg}$ aliquots of the 0.21 -g extract from 60 -g whole rye grain according to Hammann et al. [25] showed that all ARs eluted into SPE fraction 4 (49.5\% of sample mass), together with low amounts of $\beta$-sitosterol (Fig. 2), campesterol (which co-eluted with AR21:1) and traces of free fatty acids. The remaining mass originated from triacylglycerols (SPE fraction 3, 45.9\% of sample mass), hydrocarbons (SPE fraction $1,0.8 \%$ of sample mass) and steryl esters (SPE fraction 2, 3.8\% of sample mass), so that their separation from ARs could be achieved. A closer inspection of the AR-containing SPE fraction 4 (Fig. 2) indicated the presence of $\sim 90 \%$ saturated ARs and $\sim 10 \%$ alkenylresorcinols (based on peak areas). The pattern of saturated ARs, namely AR15:0 (1\%), AR17:0 (26\%), AR19:0 (37\%), AR21:0 (22\%), AR23:0 (8\%) and AR25:0 (6\%),

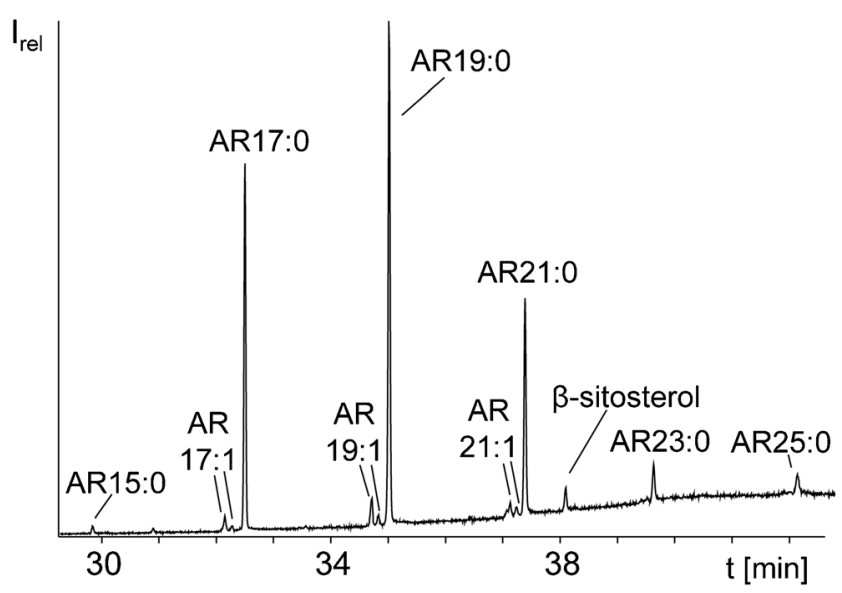

Fig. $2 \mathrm{GC} / \mathrm{MS}$ chromatogram (full scan) of the silylated content of fraction 4 after column chromatography of rye grain extract (system 2, Optima $5 \mathrm{HT}, 55^{\circ} \mathrm{C}(1 \mathrm{~min})-10^{\circ} \mathrm{C} / \mathrm{min}-200{ }^{\circ} \mathrm{C}-5^{\circ} \mathrm{C} / \mathrm{min}-320^{\circ} \mathrm{C}$ (15 min)) 
agreed well with the reported ranges for some rye species (AR17:0, 21-26\%; AR19:0, 30-35\%; AR21:0, 23-28\%; AR23:0, 8-12\% and AR25:0, 6-9\%) [8]. Further minor ARs were detected in form of monounsaturated ARs which eluted slightly earlier than the corresponding saturated ARs from the GC column (Fig. 2). Their partly low abundance and low $\mathrm{S} / \mathrm{N}$ ratio prompted us to implement a GC/MS-SIM method which should cover ARs with chain lengths of 14 to 27 carbon atoms and 0 to 4 double bonds. The required 70 molecular ions $\left(\mathrm{M}^{+}\right)$were screened in 16 time windows implemented based on the retention times of major ARs (ESM Table S1). Likewise, the three characteristic fragment ions $m / z$ 267.1, 268.1 and 281.1 of silylated ARs [28, 29] and the diagnostic base peak of silylated ring-methylated ARs (mARs) at $m / z 282.1$ (+ 14 u compared $m / z 268.1$ of silylated ARs) [30] were measured throughout the run (ESM Table S1). ARs with one keto group (oxo-ARs) were also covered by the GC/MS-SIM method because they are isobaric with conventional ARs having one carbon atom more, irrespective of the degree of saturation (ESM Table S1). For instance, AR21:0 oxo and AR22:0 as well as AR23:1 oxo and AR24:1 share the same $\mathrm{M}^{+}$, respectively. To establish the individual time windows, it was considered that isobaric ARs eluted in the order mAR $<$ AR $<$ oxo-AR [7, 30] and unsaturated ARs eluted between $\mathrm{mAR}$ and saturated ARs (mAR $<$ unsaturated ARs $<$ saturated AR < oxo-AR; AR groups with the same molecular ion range). The resulting GC/MS-SIM method enabled the additional detection of low amounts of AR27:0, AR 27:1, AR17:2, AR19:2 and even-numbered ARs (AR16:0-AR 22:0) along with traces of AR17:0 oxo, AR19:0 oxo, AR21:0 oxo and AR23:0 oxo in the silylated SPE fraction 4 of the lipid class separation. By using this sensitive GC/MSSIM method, the number of detected ARs could be more than doubled (namely 29 ARs by GC/MS-SIM versus 11 ARs by GC/MS in full scan mode). Moreover, SPE fraction 4 was dominated of ARs, so that it could directly be used for the determination of $K$ values in shake flask experiments in order to prepare a successful CCC separation.

\section{Selection of a suitable solvent system for the CCC fractionation of alkylresorcinols by means of the shake flask method}

The high logarithmic octanol/water partition coefficients $(\log P$ values) of saturated $\mathrm{ARs}(\log P, \mathrm{AR} 15: 0=8.5, \mathrm{AR} 25: 0=13.4$ [31]) are typical of nonpolar compounds and spread over five orders of magnitude. Hence, saturated ARs in the sample obtained after column chromatography were used to determine the $K$ values in five solvent systems. Similar to observations with heptane/methanol [13], $n$-hexane/methanol/water (10:91:9, v/v/ v) partitioned ARs mainly into the lower phase (Table 1). Switching to $n$-hexane/acetonitrile $(1: 1, \mathrm{v} / \mathrm{v})$ even enhanced this effect because $K_{\mathrm{U} / \mathrm{L}}$ values $(0.06-0.55)$ were roughly halved
(Table 1). Addition of the modifier benzotrifluoride in form of the BTF system ( $n$-hexane/benzotrifluoride/acetonitrile 20/7/13, $\mathrm{v} / \mathrm{v} / \mathrm{v},[32]$ ) increased the $K_{\mathrm{U} / \mathrm{L}}$ values (Table 1). However, all of them were in the low range $\left(K_{\mathrm{U} / \mathrm{L}}<0.75\right)$ and $\alpha$ values indicated an insufficient resolution. Interestingly, substitution of BTF with toluene as a modifier ( $n$-hexane/toluene/acetonitrile, 45:10:45, $\mathrm{v} / \mathrm{v} / \mathrm{v}$ [33]) provided smaller $K_{\mathrm{U} / \mathrm{L}}$ values for shorter ARs and larger $K_{\mathrm{U} / \mathrm{L}}$ values for longer ARs (Table 1). Still this solvent system was unsuited for a good AR separation, especially in the range of the shorter alkyl lengths (AR15:0-AR19:0) (Table 1). By contrast, application of the moderately nonpolar member of the HEMWat family, $n$-hexane/ethyl acetate/methanol/water (7:3:6:4, v/v/v/v) (HEMWat-4 [34]) distributed the ARs almost exclusively into the upper phase $\left(K_{\mathrm{U} / \mathrm{L}} \sim 100\right)$ (Table 1$)$. However, the least polar and stable solvent system of the HEMWat family, $n$-hexane/ethyl acetate/methanol/water (9:1:9:1, v/v/v/v, HEMWat -7), generated favourable and unique $K_{\mathrm{U} / \mathrm{L}}$ values ranging from 0.26 to 2.35 for major ARs in rye.

According to Berthod et al., the partition coefficients of a homologous family (like ARs) are linked to the alkyl chain carbon number $n C$ by Eq. 1 [35]:

$\log K=A \times n C+B$

with $K$, the $K$ value of the AR with alkyl chain carbon number $n C ; A$, the coefficient related to the $\Delta G$ of methylene transfer between the two liquid phases $(\Delta G=-R T \log K)$; and $B$, the resorcinol $K$ value in the considered system.

The $K$ values determined by experiments showed acceptably well-aligned $\log K$ values with $n C$, which were in agreement with theoretical considerations according to Eq. 1.

The software "ProMISE 2" [36] was used to predict the most appropriate number of coils to be used in the separation (1-4 coils of $\sim 120 \mathrm{~mL}$ can be freely selected with our CCC [37]). Accordingly, the use of two coils $(236 \mathrm{~mL})$ was found to be appropriate (ESM Fig. S3b), because this setup indicated a good separation of all major ARs (contrary to one 120-mL coil) (ESM Fig. S3a) within reasonable time (contrary to three $(352 \mathrm{~mL})$ (ESM Fig. S3c) or four coils). Also less and smaller CCC fractions could be collected with two coils being used. Using this setup, the $K_{\mathrm{U} / \mathrm{L}}$ values corresponded with calculated elution volumes of 60-560 mL (Fig. 3). Last but not least, this range was fully compatible with our instrument's fraction collector which allows collecting up to 80 fractions with up to $7 \mathrm{~mL}$ each. Hence, $807-\mathrm{mL}$ fractions were collected from 30 to $590 \mathrm{~mL}$.

\section{CCC separation and GC/MS-SIM analysis of the silylated fractions}

The CCC-UV chromatogram (210 nm) obtained from the injection of a 900-mg aliquot of the whole rye extract showed six distinct peaks whose elution volumes were in agreement with those simulated for the odd-numbered AR15:0 to AR25:0 
Table 1 Partitioning coefficients between the upper and lower phase ( $K_{\mathrm{U} / \mathrm{L}}$ values) of oddnumbered ARs (AR15:0 to AR25:0) determined in shake flask experiments and GC/MS for six solvent systems (mean values after triplicate)

\begin{tabular}{lllllll}
\hline & $\begin{array}{l}\mathrm{Hex} / \mathrm{EtOAc} / \\
\mathrm{MeOH} / \mathrm{H}_{2} \mathrm{O} \\
(7: 3: 6: 4)\end{array}$ & $\begin{array}{l}\mathrm{Hex} / \\
\mathrm{ACN} \\
(1: 1)\end{array}$ & $\begin{array}{l}\mathrm{Hex} / \mathrm{BTF} / \mathrm{ACN} \\
(100: 35: 65)\end{array}$ & $\begin{array}{l}\mathrm{Hex} / \mathrm{Tol} / \mathrm{ACN} \\
(45: 10: 45)\end{array}$ & $\begin{array}{l}\mathrm{Hex} / \mathrm{MeOH} / \\
\mathrm{H}_{2} \mathrm{O}(100: 91: 9)\end{array}$ & $\begin{array}{l}\mathrm{Hex} / \mathrm{EtOAc} / \\
\mathrm{MeOH} / \mathrm{H}_{2} \mathrm{O} \\
(9: 1: 9: 1)\end{array}$ \\
\hline AR15:0 & $\sim 100$ & 0.06 & 0.34 & 0.16 & 0.09 & 0.26 \\
AR17:0 & $\sim 100$ & 0.08 & 0.37 & 0.18 & 0.16 & 0.35 \\
AR19:0 & $\sim 100$ & 0.10 & 0.42 & 0.25 & 0.20 & 0.52 \\
AR21:0 & $\sim 100$ & 0.17 & 0.51 & 0.39 & 0.37 & 0.90 \\
AR23:0 & $\sim 100$ & 0.33 & 0.58 & 0.69 & 0.79 & 1.71 \\
AR25:0 & $\sim 100$ & 0.55 & 0.71 & 1.18 & 1.46 & 2.35 \\
\hline
\end{tabular}

(Fig. 3a vs. ESM Fig. S3b). However, GC/MS-SIM inspection of individual fractions enabled the detection of more than one AR per fraction. For instance, CCC fraction $14(121-128 \mathrm{~mL})$ not only featured AR17:0 but also AR19:1 isomers, AR21:2 and traces of AR18:0 (Fig. 3a, b). Elution of AR17:0, AR19:1 isomers and AR21:2 into one CCC fraction indicated that presence of a double bond in the alkyl chain of ARs had a similar effect

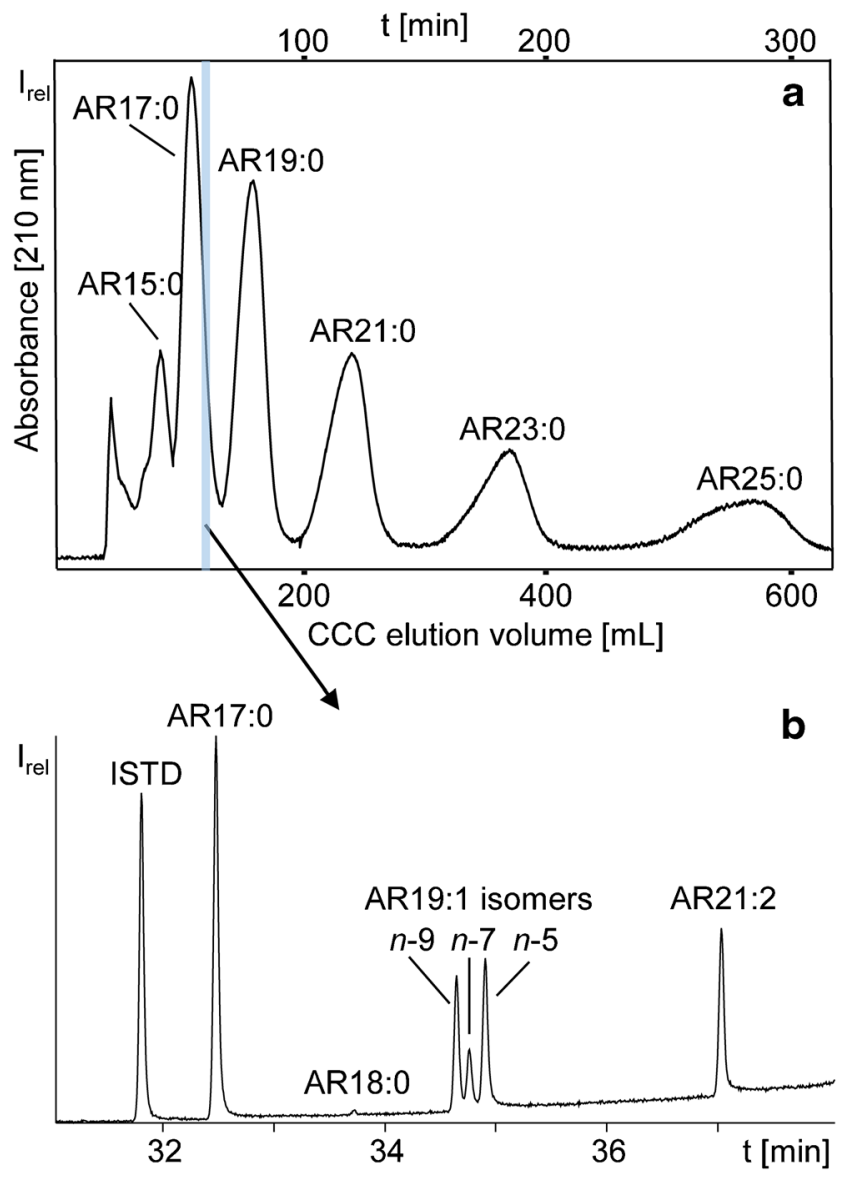

Fig. 3 a CCC/UV chromatogram $(210 \mathrm{~nm})$ of the separation of ARs from rye grain extract with the solvent system $n$-hexane/ethyl acetate/methanol/water $(9: 1: 9: 1, \mathrm{v} / \mathrm{v} / \mathrm{v} / \mathrm{v})$. Separation was performed in head-to-tail mode at a flow rate of $2 \mathrm{~mL} / \mathrm{min}$, with $S_{\mathrm{f}}=86 \%$, coil volume of $236 \mathrm{~mL}$ and $22{ }^{\circ} \mathrm{C}$. b GC/MS chromatogram (full scan) of fraction 14 collected from 121 to $128 \mathrm{~mL}$ (EV 37.3-40.3\%) after silylation (system 2, Optima $5 \mathrm{HT}, 55^{\circ} \mathrm{C}(1 \mathrm{~min})-10{ }^{\circ} \mathrm{C} / \mathrm{min}-200{ }^{\circ} \mathrm{C}-5{ }^{\circ} \mathrm{C} / \mathrm{min}-320{ }^{\circ} \mathrm{C}$ (15 min)) on the CCC elution as two additional carbon atoms (Fig. 4). This relation resembled the effect of double bonds on the elution of fatty acids and their methyl esters according to the so-called equivalent chain length (ECL) rule [38, 39]. Similar rules were also developed for other lipid classes and proved to be helpful for the prediction of co-elutions [40]. Moreover, several AR19:1 isomers were detected by GC/MS which could not be resolved by CCC (Fig. 3).

The full evaluation of the sample was based on the normalization mode according to Hammann et al. which reports results independent of fraction or coil volumes [16] (Eq. 2):

$\mathrm{EV}=\frac{V_{m}-V_{e}}{V_{c}} \times 100 \%=\frac{V_{m}-33 \mathrm{~mL}}{236 \mathrm{~mL}} \times 100 \%$

with $\mathrm{EV}$, the corrected elution volume in percent; $V_{m}$, the volume of mobile phase; $V_{e}$, the volume of extruded stationary phase (here $33 \mathrm{~mL}$ ); and $V_{c}$, the total coil volume (here $236 \mathrm{~mL}$ ).

EV values of ARs calculated according to Eq. 2 were in good agreement with $K_{\mathrm{U} / \mathrm{L}}$ values determined by shake flask experiments (when transferred on $\%$ scale). To convert the $K_{\mathrm{U} / \mathrm{L}}$ values into their corresponding $\mathrm{EV}$ values, the $K_{\mathrm{U} / \mathrm{L}}$ values are simply multiplied by the $S_{\mathrm{f}}$ value [\%] $(\mathrm{EV}=K \bullet$ $S_{\mathrm{f}}$ ). For instance, the (shake flask-derived) $K_{\mathrm{U} / \mathrm{L}}$ value 0.26 of AR15:0 resulted in an EV value of $(0.26 \cdot 86 \%=) 22.4 \%$ while its EV value after CCC separation ranged from 16.5 to $31.4 \%$ (mean EV 23.9\%). In addition to ARs, low amounts of the free fatty acids linoleic acid (18:2n-6, EV 132.2-153\%), oleic acid (18:1n-9, EV 167.8-212.3\%) and palmitic acid (16:0, EV 158.9-212.3\%) were also detectable in several fractions, but will not be considered further below. ARs were detected from CCC fraction 5 to $\mathrm{CCC}$ fraction 80 (end of fractionation) (Fig. 4). As anticipated, CCC fractionation enabled the detection of further, partly uncommon/unknown ARs than without CCC. For a better description, ARs will be discussed in groups.

\section{Alkylresorcinols with saturated alkyl chains}

In head-to-tail mode (lower phase mobile), saturated ARs eluted with increasing chain length (Fig. 4). The elution volumes 
Fig. 4 Corrected CCC elution volume of the ARs from rye grain after separation with the solvent system $n$-hexane/ethyl acetate/ methanol/water $(9: 1: 9: 1, \mathrm{v} / \mathrm{v} / \mathrm{v} / \mathrm{v})$ in head-to-tail mode, $2 \mathrm{~mL} / \mathrm{min}$ flow rate and $S_{\mathrm{f}}=86 \%$

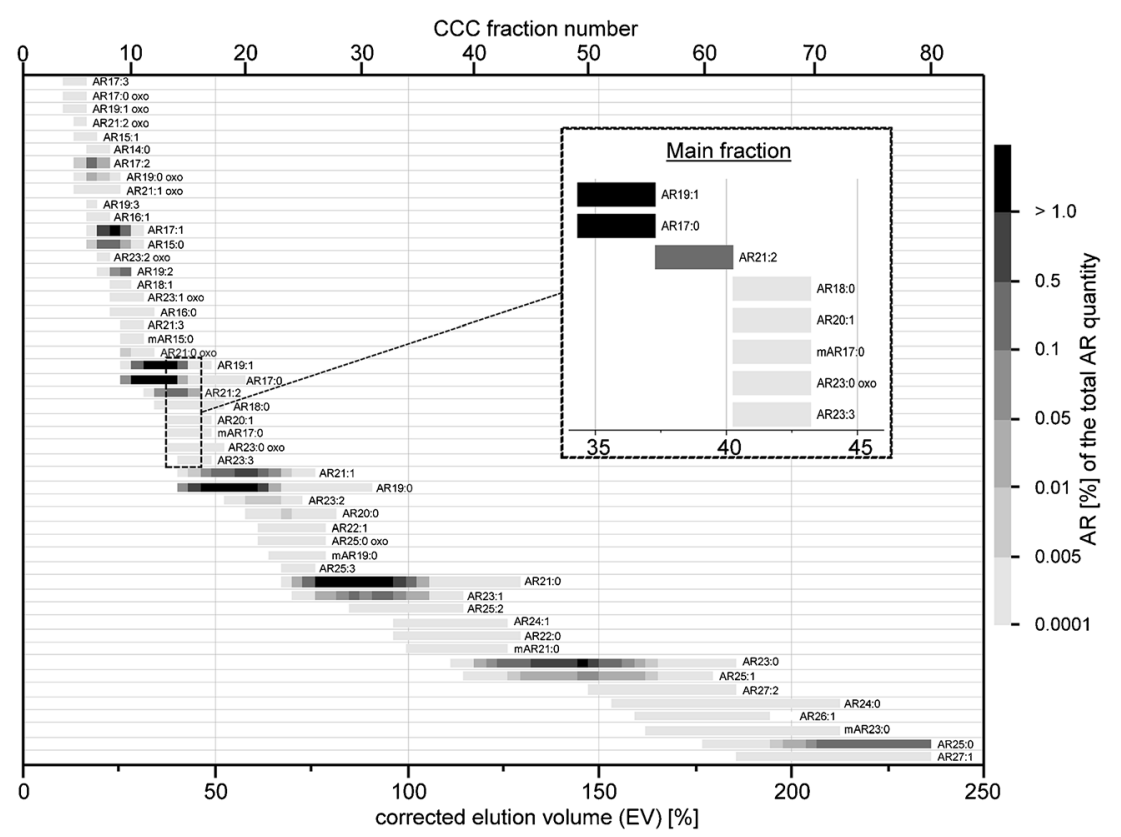

of the individual saturated compounds increased exponentially according to Eq. 1 for the relationship of the homologous compounds (Fig. 4). Odd-numbered (classic) saturated ARs (AR15:0-AR25:0) were detected in almost all CCC fractions (7-80, EV 16.5-236\%) and were the dominant ARs. For instance, AR17:0, AR19:0 and AR23:0 together accounted for $\sim 75 \%$ of the total AR content (Table 2). Shorter or longer odd-numbered ARs were not detected. However, the sensitive GC/MS-SIM method enabled the detection of even-numbered ARs even in the ppm range $(0.0001-0.0232 \%$ share of the alkylresorcinols). Even-numbered ARs eluted between the respective odd-numbered representatives. Besides the known even-numbered AR16:0-AR24:0 in rye, AR14:0 (CCC fractions 6-8) was detected in rye for the first time. Accordingly, AR14:0 represented the AR with the shortest alkyl chain in the rye sample.

\section{Alkylresorcinols with unsaturated alkyl chains (alkenylresorcinols)}

Alkenylresorcinols with one $(n=29)$, two $(n=6)$ and three $(n=5)$ double bonds were detected as well (Table 2). Monounsaturated alkenylresorcinols covered thirteen subsequent chain lengths, including traces of even-numbered ones (AR16:1-AR26:1) and noticeably higher proportions of oddnumbered (AR15:1-AR27:1) members. For instance, members with the predominant chain lengths (AR17:1 (3\%), AR19:1 (6.3\%) and AR21:1 (3\%)) contributed with > 12\% to the AR content of the rye sample (Table 2). Three AR27:1 isomers were detected but not the corresponding AR27:0 due to its $K$ value outside the fractionation range $(K>2.7)$. However, AR27:0 was detected together with triacylglycerols, $\beta$-sitosterol and campesterol in the fraction obtained by elution-extrusion of the complete coil volume (data not shown).

For most monounsaturated ARs, three isomers were found (e.g. AR19:1 (Fig. 3b, Table 2). The $t_{\mathrm{R}}$ distance and range of monounsaturated ARs in GC was almost the same for all isomer groups (overall $\Delta t_{\mathrm{R}} \sim 0.12 \mathrm{~min}$, ESM Fig. S4) which indicated double bonds in characteristic positions. However, the abundance ratio of three peaks was not uniform; i.e., the first, second or third isomer could be the most abundant one, respectively (ESM Fig. S4). In literature, double bonds of odd-numbered monounsaturated ARs (AR17:1-AR23:1) were assigned to $n-5-, n$-7- and n-9-positions by collisionactivated dissociation (CAD) tandem mass spectrometry analysis [41]. However, double bond positions in evennumbered monounsaturated ARs like AR22:1 (Fig. 5) and other minor ARs had not been determined, yet. For this purpose, we prepared DMDS adducts from several CCC fractions in order to confirm known structures and to clarify those of unknown ARs (Table 2). GC/MS chromatograms of derivatized CCC fractions showed two peaks for each AR which differed by $\sim 2.6 \mathrm{~min}$ in $t_{\mathrm{R}}$. Noteworthy, two adducts were also observed for saturated silylated ARs (Fig. 6a). As shown by Knödler et al., one or two methyl sulfide groups can also be added to resorcinol moiety [19]. Hence, saturated ARs formed ions representing the substitutions of $\mathrm{H}$ by $\mathrm{SCH}_{3}$ (added mass $46 \mathrm{u}$ ) or $2 \mathrm{x} \mathrm{H}$ by $2 \mathrm{x} \mathrm{SCH}_{3}(92 \mathrm{u}$ )). Accordingly, the molecular ion of peak 1 was $46 \mathrm{u}$ higher than the corresponding AR (DMDS-mono adduct 1, e.g. $\mathrm{M}^{+}$, [TMS-O-AR17:0+ $\left.\mathrm{SCH}_{3}-\mathrm{H}\right]^{+}=m / z$,538) while the second peak was $92 \mathrm{u}$ higher in mass (DMDS adduct 2, e.g. $\mathrm{M}^{+}$, [TMS-O-AR17:0+2 $\left.\mathrm{SCH}_{3}-2 \mathrm{H}\right]^{+}=m / z$ 584) (Fig. 6b). 
Table 2 Alkylresorcinols in rye grains identified by GC/MS-SIM analysis after CCC fractionation

\begin{tabular}{|c|c|c|c|c|c|c|}
\hline Alkylresorcinol & $\mathrm{GC}$ retention time $(\mathrm{min})$ & $\begin{array}{l}\text { Contribution to total } \\
\text { alkylresorcinols }\end{array}$ & $\mathrm{CCC}$ fractions & Main fraction & $\begin{array}{l}\text { CCC elution } \\
\text { order }^{\mathrm{a}}\end{array}$ & Reference \\
\hline \multicolumn{2}{|l|}{ Saturated } & \multicolumn{5}{|l|}{$85.3 \%$} \\
\hline AR14:0 & 28.48 & $\operatorname{tr}^{\mathrm{b}}$ & $6-8$ & 7 & 6 & \\
\hline AR15:0 & 29.86 & $0.8 \%$ & $7-11$ & 8 & 13 & {$[6,8,9]$} \\
\hline AR16:0 & 31.19 & $\operatorname{tr}^{\mathrm{b}}$ & $9-12$ & 10 & 18 & {$[6]$} \\
\hline AR17:0 & 32.50 & $23.0 \%$ & $10-20$ & 13 & 23 & {$[6,8,9]$} \\
\hline AR18:0 & 33.77 & $\operatorname{tr}^{\mathrm{b}}$ & $13-18$ & 15 & 25 & {$[6]$} \\
\hline AR19:0 & 35.00 & $27.7 \%$ & $15-31$ & 20 & 31 & {$[6,8,9]$} \\
\hline AR20:0 & 36.21 & $\operatorname{tr}^{\mathrm{b}}$ & $21-28$ & 24 & 33 & {$[6]$} \\
\hline AR21:0 & 37.38 & $24.4 \%$ & $24-44$ & 31 & 38 & {$[6,8,9]$} \\
\hline AR22:0 & 38.51 & $\operatorname{tr}^{\mathrm{b}}$ & $34-44$ & 37 & 42 & {$[6]$} \\
\hline AR23:0 & 39.62 & $6.5 \%$ & $39-72$ & 50 & 44 & {$[6,8,9]$} \\
\hline AR24:0 & 40.80 & $\operatorname{tr}^{\mathrm{b}}$ & $54-72$ & 60 & 47 & {$[6]$} \\
\hline AR25:0 & 42.18 & $2.9 \%$ & $61-80$ & 78 & 50 & {$[6,8,9]$} \\
\hline \multicolumn{2}{|l|}{ Monounsaturated $^{\mathrm{c}}$} & \multicolumn{5}{|l|}{$13.6 \%$} \\
\hline AR15:1 & $29.60(n-7), 29.76(n-5)$ & $\operatorname{tr}^{\mathrm{b}}$ & $6-7$ & 7 & 5 & \\
\hline AR16:1 & $30.76(n-9)$ & $\operatorname{tr}^{\mathrm{b}}$ & $7-8$ & 8 & 11 & \\
\hline AR17:1 & $32.17(n-9), 32.29(n-7), 32.45(n-5)$ & $3.0 \%$ & $7-11$ & 10 & 12 & {$[6,41]$} \\
\hline AR18:1 & $33.45(n-9), 33.55(n-7)$ & $\operatorname{tr}^{\mathrm{b}}$ & $9-10$ & 10 & 16 & \\
\hline AR19:1 & $34.73(n-9), 34.84(n-7), 34.98(n-5)$ & $6.3 \%$ & $10-17$ & 13 & 22 & {$[6,41]$} \\
\hline AR20:1 & $35.93(n-9), 36.14(n-7)$ & $\operatorname{tr}^{\mathrm{b}}$ & $14-17$ & 15 & 26 & \\
\hline AR21:1 & $37.13(n-9), 37.25(n-7), 37.38(n-5)$ & $3.0 \%$ & $15-26$ & 20 & 30 & {$[6,41]$} \\
\hline AR22:1 & $38.29(n-9), 38.39(n-7)$ & $\operatorname{tr}^{\mathrm{b}}$ & $22-27$ & 23 & 34 & \\
\hline AR23:1 & $39.42(n-9), 39.52(n-7), 39.63(n-5)$ & $0.9 \%$ & $25-39$ & 33 & 39 & {$[6,41]$} \\
\hline AR24:1 & $40.57(n-9), 40.68(n-7)$ & $\operatorname{tr}^{\mathrm{b}}$ & $34-43$ & 39 & 41 & \\
\hline AR25:1 & $41.90(n-9), 42.02(n-7), 42.16(n-5)$ & $0.4 \%$ & $40-61$ & 51 & 45 & {$[6]$} \\
\hline AR26:1 & $43.40(n-9)$ & $\operatorname{tr}^{\mathrm{b}}$ & $55-68$ & 59 & 48 & \\
\hline AR27:1 & $45.16(n-9), 45.30(n-7), 45.50(n-5)$ & $\operatorname{tr}^{\mathrm{b}}$ & $64-80$ & 79 & 51 & {$[6]$} \\
\hline \multicolumn{2}{|l|}{ Diunsaturated } & \multicolumn{5}{|l|}{$1.0 \%$} \\
\hline AR17:2 & 32.13 & $0.2 \%$ & $6-8$ & 7 & 7 & {$[6]$} \\
\hline AR19:2 & 34.70 & $0.3 \%$ & $8-10$ & 10 & 15 & {$[6,41]$} \\
\hline AR21:2 & 37.14 & $0.5 \%$ & $12-16$ & 14 & 24 & {$[6,41]$} \\
\hline AR23:2 & 39.43 & $\operatorname{tr}^{\mathrm{b}}$ & $19-25$ & 22 & 32 & {$[6,41]$} \\
\hline AR25:2 & 41.91 & $\operatorname{tr}^{\mathrm{b}}$ & $30-39$ & 34 & 40 & {$[6,41]$} \\
\hline AR27:2 & 45.17 & $\operatorname{tr}^{\mathrm{b}}$ & $51-63$ & 56 & 46 & {$[6]$} \\
\hline \multicolumn{7}{|l|}{ Triunsaturated } \\
\hline AR17:3 & 32.24 & $\operatorname{tr}^{\mathrm{b}}$ & $5-6$ & 5 & 1 & {$[6]$} \\
\hline AR19:3 & 34.82 & $\operatorname{tr}^{\mathrm{b}}$ & 7 & 7 & 10 & {$[6]$} \\
\hline AR21:3 & 37.26 & $\operatorname{tr}^{\mathrm{b}}$ & $10-11$ & 11 & 19 & {$[6]$} \\
\hline AR23:3 & 39.55 & $\operatorname{tr}^{\mathrm{b}}$ & $15-17$ & 16 & 29 & {$[6]$} \\
\hline AR25:3 & 42.10 & $\operatorname{tr}^{\mathrm{b}}$ & $24-26$ & 25 & 37 & \\
\hline \multicolumn{7}{|l|}{$\mathrm{mAR}$} \\
\hline mAR15:0 & 30.56 & $\operatorname{tr}^{\mathrm{b}}$ & $10-11$ & 10 & 20 & \\
\hline mAR17:0 & 33.20 & $\operatorname{tr}^{\mathrm{b}}$ & $14-17$ & 15 & 27 & \\
\hline mAR19:0 & 35.69 & $\operatorname{tr}^{\mathrm{b}}$ & $23-27$ & 24 & 36 & \\
\hline $\mathrm{mAR} 21: 0$ & 38.05 & $\operatorname{tr}^{\mathrm{b}}$ & $35-43$ & 39 & 43 & \\
\hline mAR23:0 & 40.31 & $\operatorname{tr}^{\mathrm{b}}$ & $56-72$ & 62 & 49 & \\
\hline \multicolumn{7}{|l|}{ AR oxo ${ }^{c}$} \\
\hline AR17:0 oxo & 33.98 & $\operatorname{tr}^{\mathrm{b}}$ & $5-6$ & 5 & 2 & \\
\hline
\end{tabular}


Table 2 (continued)

\begin{tabular}{|c|c|c|c|c|c|c|}
\hline Alkylresorcinol & GC retention time (min) & $\begin{array}{l}\text { Contribution to total } \\
\text { alkylresorcinols }\end{array}$ & CCC fractions & Main fraction & $\begin{array}{l}\text { CCC elution } \\
\text { order }^{\mathrm{a}}\end{array}$ & Reference \\
\hline AR19:0 oxo & 36.45 & $\operatorname{tr}^{\mathrm{b}}$ & $6-9$ & 7 & 8 & [7] \\
\hline AR21:0 oxo & 38.78 & $\operatorname{tr}^{\mathrm{b}}$ & $10-12$ & 10 & 21 & [7] \\
\hline AR23:0 oxo & 41.15 & $\operatorname{tr}^{\mathrm{b}}$ & $14-18$ & 14 & 28 & [7] \\
\hline AR25:0 oxo & 44.16 & $\operatorname{tr}^{\mathrm{b}}$ & $22-27$ & 25 & 35 & [7] \\
\hline AR19:1 oxo & $36.16(n-9), 36.27(n-7), 36.42(n-5)$ & $\operatorname{tr}^{\mathrm{b}}$ & $5-6$ & 7 & 3 & {$[10]$} \\
\hline AR21:1 oxo & $38.53(n-9), 38.64(n-7), 38.76(n-5)$ & $\operatorname{tr}^{\mathrm{b}}$ & $6-9$ & 8 & 9 & {$[7,10]$} \\
\hline AR23:1 oxo & $40.89(n-9), 41.00(n-7), 41.14(n-5)$ & $\operatorname{tr}^{\mathrm{b}}$ & $9-11$ & 11 & 17 & {$[7,10]$} \\
\hline AR21:2 oxo & 38.51 & $\operatorname{tr}^{\mathrm{b}}$ & 6 & 6 & 4 & {$[10]$} \\
\hline AR23:2 oxo & 40.87 & $\operatorname{tr}^{\mathrm{b}}$ & 8 & 8 & 14 & [10] \\
\hline
\end{tabular}

${ }^{a}$ Numbering based on CCC elution order (Fig. 4)

${ }^{\mathrm{b}}$ Trace amounts, contribution $<0.1 \%$ to the total alkylresorcinols content

${ }^{\mathrm{c}}$ Several isomers; GC retention time indicates the amount of isomers with the position of double bond

This reaction in the aromatic part was also observed in the case of monounsaturated ARs, along with the addition of two $\mathrm{SCH}_{3}$ units in the alkyl chain. Hence, in the case of monounsaturated ARs, three or four $\mathrm{SCH}_{3}$ units were added. Therefore, the corresponding peaks were shifted by $(46+94) \mathrm{u}$ (adduct 1) and (94+ 94) $\mathrm{u}$ (adduct 2) to higher mass. For instance, after reaction with DMDS and subsequent silylation of AR19:1, the resulting TMS$O$-AR19:1 ( $m / z, 518)$ generated peaks, namely one peak with $\mathrm{M}^{+}$

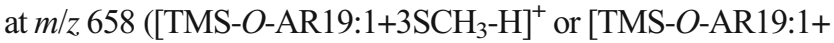
$140 \mathrm{u}^{+}$(Fig. 6c) and one peak with $\mathrm{M}^{+}$at $m / z 704$ ([TMS-O-

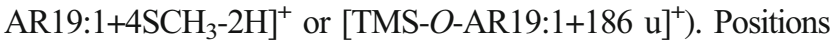
of double bonds can be determined by the fragment ions that were formed during the cleavage of the $\mathrm{C}-\mathrm{C}$ bond between the $\mathrm{CH}_{3} \mathrm{~S}$ substituents in the alkyl chain, with charge on the left hand and the right hand sides, respectively (Fig. 6d) [20]. The nominal $m / z$ values for these key fragments belong to the series $m / z(61+$ $m \cdot 14$ ) for fragment ions including the terminal part of the alkyl chain $\left(\left[\mathrm{H}\left(\mathrm{CH}_{2}\right)_{\mathrm{m}} \mathrm{CH}=\mathrm{SCH}_{3}\right]^{+}\right)[20]$ and $m / z(359+n \cdot 14)$ for fragment ions including the head group (i.e. the silylated resorcinol moiety $\left(\left[\mathrm{CH}_{3} \mathrm{~S}=\mathrm{CH}\left(\mathrm{CH}_{2}\right)_{n} \mathrm{C}_{6} \mathrm{H}_{2} \mathrm{SCH}_{3}\left(\mathrm{OSi}\left(\mathrm{CH}_{3}\right)_{3}\right)_{2}\right]^{+}\right)$ (DMDS adduct 1) and corresponding fragment ions added together result in the molecular ion (e.g. AR19:1n-9 DMDS adduct 1, $m / z(173+485=) 658$ (Fig. 6c, d, ESM Table S2).

Accordingly, the most important key fragment ions of monounsaturated ARs with a double bond in n-9-, n-7- and $n$-5-positions are $m / z, 173(\mathrm{~m} / \mathrm{z} 61+8 \bullet 14), \mathrm{m} / \mathrm{z} 145(\mathrm{~m} / \mathrm{z}, 61+$ $6 \cdot 14)$ and $m / z 117(\mathrm{~m} / \mathrm{z} 61+4 \cdot 14)$, respectively (ESM Table S2). These measurements verified the presence of three AR 19:1 isomers which eluted in the order (silylated) AR19:1n-9 < AR19:1n-7 < AR19:1n-5 (Fig. 6a). The corresponding three isomers were detected for all odd-numbered monounsaturated AR17:1-AR25:1 except for AR15:1 which lacked the $n$-9-isomer (Table 2). Moreover, the evennumbered monounsaturated ARs featured two isomers with double bonds in $n-7$ and $n-9$ positions for AR18:1-AR24:1 along with AR16:1n-9 and AR26:1n-9 being the sole isomer, respectively (Table 2 ).

Diunsaturated ARs were generally odd-numbered and featured only one isomer, respectively, from AR17:2 to AR27:2 (Table 2). AR17:2, AR19:2 and AR21:2 contributed with 0.2$0.5 \%$, respectively, to total ARs, whereas the others were only found in traces (Table 2). In all six occasions, the diunsaturated homologue almost co-eluted (GC) with the first eluting monounsaturated isomer $\left(\Delta t_{\mathrm{R}}=0.01-0.03 \mathrm{~min}\right.$, Table 2). This indicated that also double bonds of diunsaturated odd-chain ARs were located in the same positions (Table 2). Plots of $\log t_{\mathrm{R}}$ against the carbon number in the alkyl chain resulted in stacked straight lines for diunsaturated ARn:2 and monounsaturated ARn:1n-9 homologues (Fig. 7a). Suzuki et al. described the presence of cisconfigured n-6- and n-9-double bonds in ARs [41].

Similar to the other ARs, diunsaturated ARs formed two DMDS adducts which differed by $46 \mathrm{u}$ in mass. Interpretation of the mass spectra obtained from DMDS adducts in molecules with two nearby double bonds (here, methyleneinterrupted) was found to be equivocal due to the possible formation of heterocyclic thietane, tetrahydrothiophene and tetrahydrothiopyran structures (4-, 5- and 6-membered rings) [42]. In the present case, however, the position of the terminal double bond at $n$ - 6 -position could be verified by means of $m / z$ $131(\mathrm{~m} / \mathrm{z}, 61+5 \cdot 14)($ ESM Fig. S5). In addition, the position of the second double bond of AR21:2 $\left(\left[\mathrm{C}_{36} \mathrm{H}_{68} \mathrm{~S}_{4} \mathrm{Si}_{2} \mathrm{O}_{2}\right]^{+}\right)$ could be assigned to $n$-9-position by means of $m / z 513$ $\left(\left[\mathrm{C}_{26} \mathrm{H}_{49} \mathrm{~S}_{2} \mathrm{Si}_{2} \mathrm{O}_{2}\right]^{+}\right)$in DMDS adduct 1 (ESM Fig. S5). In contrast to $\mathrm{m} / \mathrm{z} 131$, this fragment ion increases by $\mathrm{m} / \mathrm{z} 513$ $\pm 14 \cdot n$ with increasing chain length of the AR. The close relationship of GC retention times with the first eluting monounsaturated isomer (see above) indicated that all diunsaturated ARs featured the double bonds in $n-6$ - and $n$ - 9 -positions, respectively (Fig. 7a). 

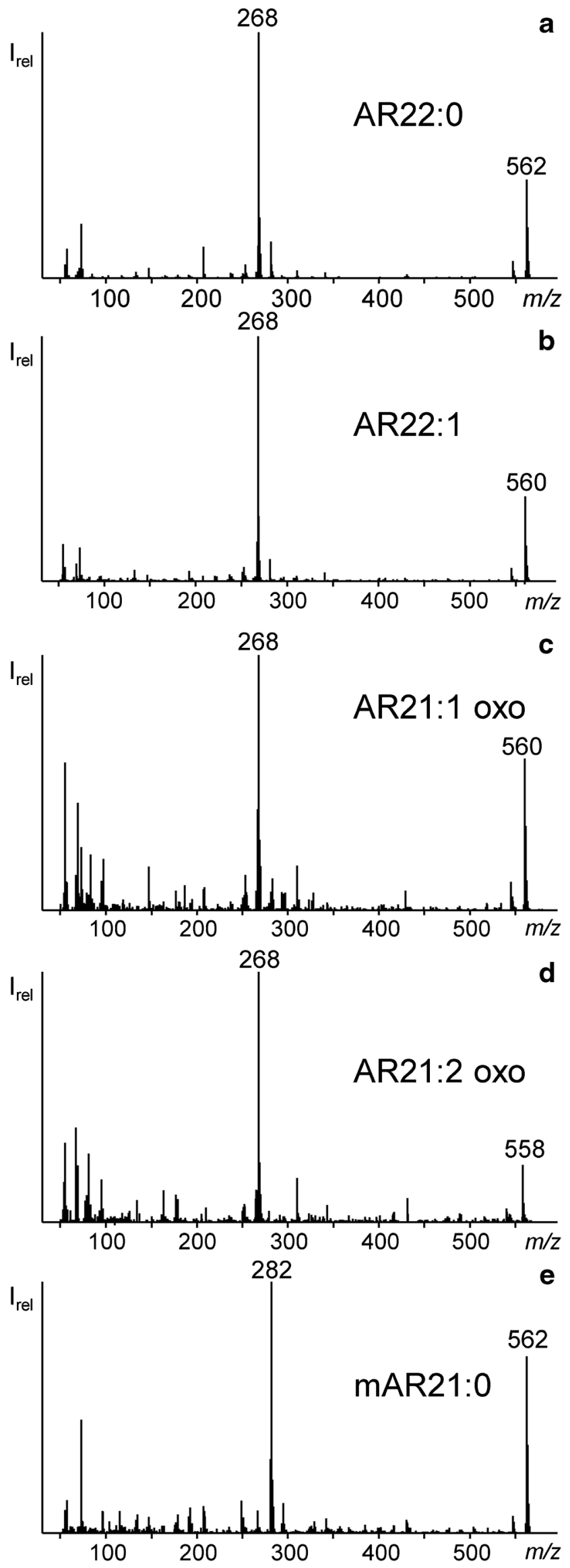

Fig. 5 GC/MS spectra of the TMS derivatives of (a) AR22:0 (38.52-min retention time), (b) AR22:1 (38.39-min retention time), (c) AR21:1 oxo (38.76-min retention time), (d) AR21:2 oxo (38.51-min retention time) and (e) mAR21:0 (38.05-min retention time) with their molecular ion and the typical base ion of $m / z, 268$ for AR and $m / z, 282$ for $\mathrm{mAR}$

Finally, CCC fractionation enabled the detection of traces of five odd-numbered triunsaturated ARs including AR17:3 to AR23:3 (previously described in rye [6]) along with AR25:3 (Table 2). Unfortunately, positions and configurations of the double bonds could not be determined with the DMDS adduct method (data not shown). The triunsaturated ARs eluted

$\mathrm{I}_{\text {rel }}$
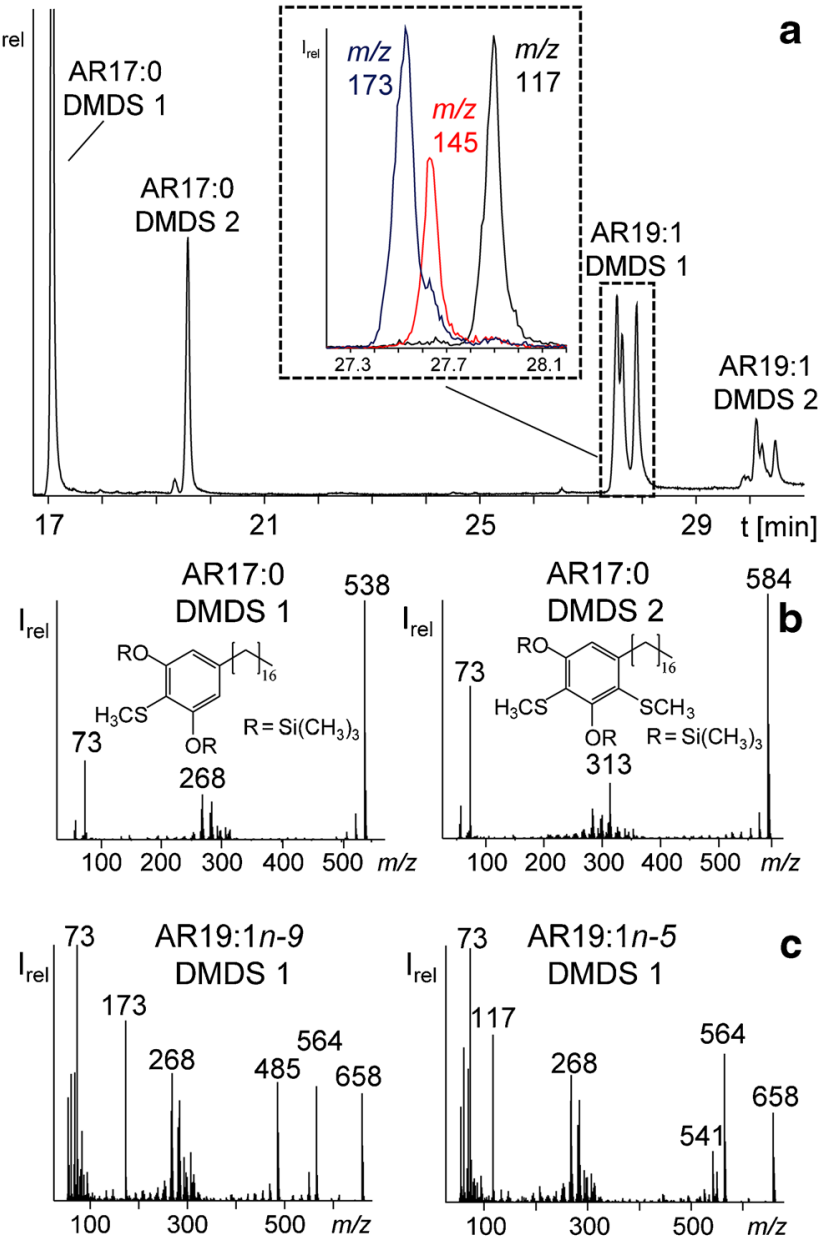

AR19:1

DMDS 2

AR19:1

DMDS 1
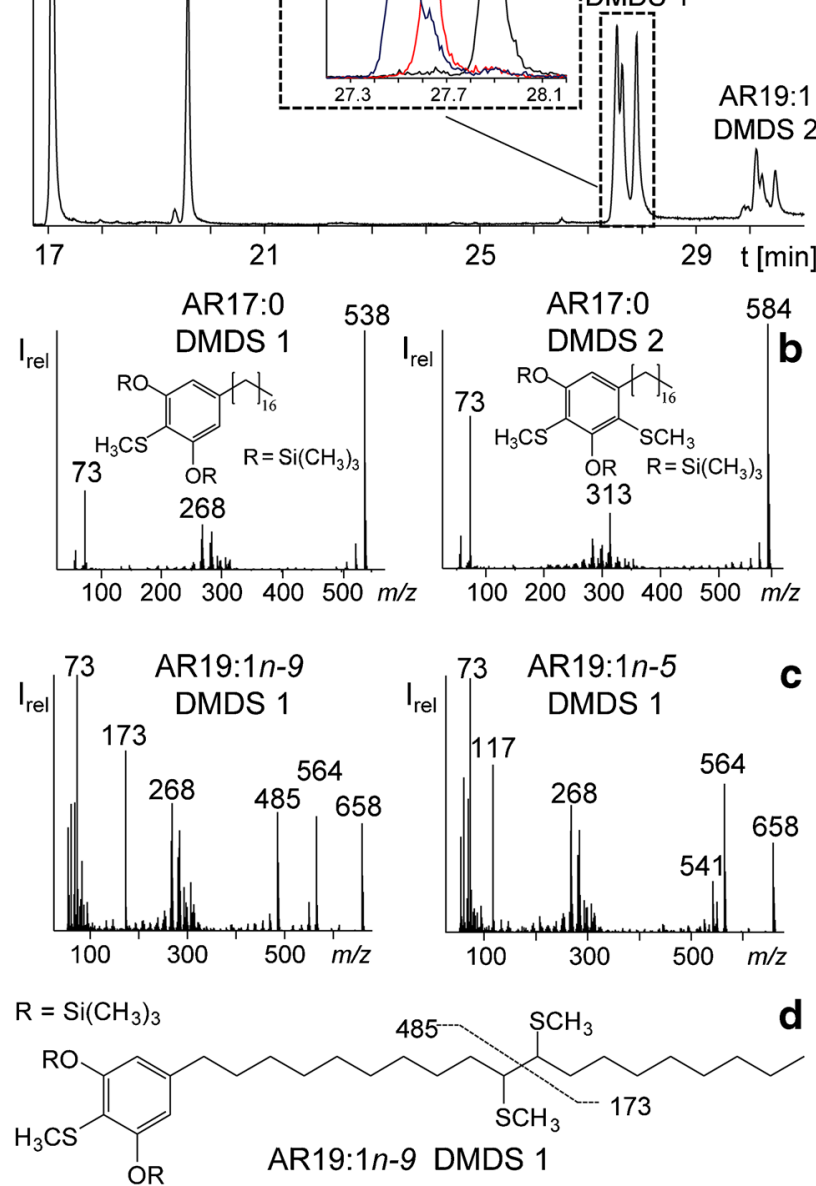

Fig. 6 a GC/MS chromatogram (full scan) of the DMDS adducts of fraction 14 after $\mathrm{CCC}$ separation with a small section of the fragment ions $\mathrm{m} / \mathrm{z} 173,145,117$ (system $1, \mathrm{ZB}-1 \mathrm{HT}, 100{ }^{\circ} \mathrm{C}(1 \mathrm{~min})-10{ }^{\circ} \mathrm{C} / \mathrm{min}-$ $\left.250{ }^{\circ} \mathrm{C}(5 \mathrm{~min})-5^{\circ} \mathrm{C} / \mathrm{min}-300^{\circ} \mathrm{C}-30^{\circ} \mathrm{C} / \mathrm{min}-350{ }^{\circ} \mathrm{C}(10 \mathrm{~min})\right)$. b Mass spectra of the DMDS adducts (1+2) of AR17:0. $\mathbf{c}$ Mass spectra of the DMDS adduct 1 of AR19:1n-9 and AR19:1n-5. d Structure of AR19:1n-9 with shown fragmentation 

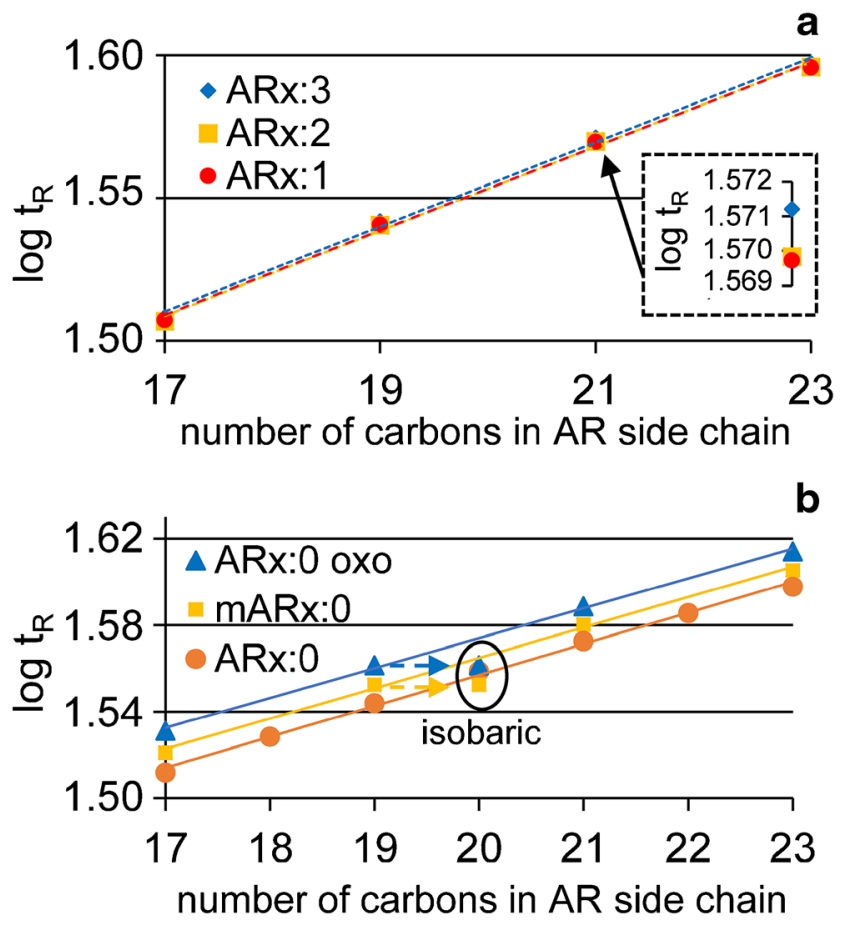

Fig. 7 Plots of the logarithmic retention time against the carbon number in the alkyl chain of (a) triunsaturated ARs (ARx:3, $y=0.0148 \mathrm{x}+1.2589$, $R^{2}=0.9968$ ), diunsaturated ARs (ARx: $2, y=0.0148 \mathrm{x}+1.257, R^{2}=$ 0.9968 ) and monounsaturated $n-9$ ARs (ARx: $1, y=0.0147 \mathrm{x}+1.259$, $R^{2}=0.9970$ ), and (b) saturated ARs with a keto group (ARx:0 oxo, $y=$ $0.0143 \mathrm{x}+1.2882, R^{2}=0.9988$ ), saturated ARs (ARx:0, $y=0.0152 \mathrm{x}+$ $\left.1.2544, R^{2}=0.9987\right)$ and saturated mARs (mARx:0, $y=0.0148 \mathrm{x}+$ $\left.1.2703, R^{2}=0.9987\right)$. The correlation of the individual groups was calculated from 17 to $21 \mathrm{C}$ atoms in the alkyl chain based on the temperature program. Extrapolation of AR19:0 oxo and mAR19:0 was plotted to isobaric saturated AR20:0

0.12 min after the corresponding diunsaturated ARs from the GC/MS column (exception AR25:3, due to final oven temperature). Plots of $\log t_{\mathrm{R}}$ against the carbon number in the alkyl chain resulted in straight lines for triunsaturated ARs, which was different from the abovementioned di- and monounsaturated ARs (Fig. 7a). This also produced strong evidence that the double bonds of all homologues were always in the same positions (counted from the tail end).

In $\mathrm{CCC}$, the elutions of the unsaturated ARs followed the abovementioned ECL rule (one double bond reduced the CCC elution volume by two carbons). Accordingly, AR17:0, AR19:1, AR21:2 and AR23:3 were found in the same elution range (Fig. 4). However, in dependence of the amount, ARs were present in more or less CCC fractions. ARs found in traces were only detected in one CCC fraction while abundant ARs were eluting in ten or more CCC fractions (Fig. 4). In addition, the more double bonds were present in a compound, the weaker the effect of the ECL, so a slight separation of the ECL pairs was possible (recognizable by the respective main fractions of the compounds) (Fig. 4, Table 2).
Alkylresorcinols with keto groups in the alkyl chain

ARs with a keto group (oxo-ARs) showed higher $\mathrm{GC} t_{\mathrm{R}}$ than the isobaric (saturated) ARs. Hence, both groups of ARs could be distinguished from each other [7]. Also, plots of $\log t_{\mathrm{R}}$ against the carbon number in the alkyl chain resulted in straight lines for both saturated ARs and oxo-ARs (Fig. 7b). Extrapolation of the oxo-ARs to isobaric saturated ones (exemplarily shown in Fig. 7b for AR20:0 and AR19:0 oxo) verified constantly higher GC retention times of oxo-ARs. Seitz et al. assigned the keto group of oxo-ARs to $\beta$-position (i.e. $\mathrm{C} 2$ on the alkyl chain) which corresponds with a series of 5-(2-oxoalk(en)yl)resorcinols [7]. Apparently, oxo-ARs were formed by $\beta$-oxidation. The pattern of odd-numbered oxo-ARs from $R=\mathrm{C}_{17}-\mathrm{C}_{25}(4 / 50 / 28 / 15 / 5$; values rounded) was similar but not in full agreement with the corresponding saturated ARs (27/33/29/8/3; values rounded).

Despite the observed differences in GC retention times, an even better distinction was possible by the distinctly different CCC elution profiles of oxo-ARs and isobaric $n$-alkyl-ARs. The higher polarity of oxo-ARs strongly accelerated their CCC elution compared with conventional ARs with the same alkyl length. Consequently, oxo-ARs eluted many CCC fractions earlier than the isobaric conventional ARs (which corresponded with a compensatory effect of $\sim 5$ additional carbon atoms or three double bonds. For example, the main CCC fraction of AR23:0 oxo (CCC fraction 14) was also the main CCC fraction of AR18:0 and AR23:3 (Fig. 4). Hence, CCC fractionation could provide equivocal information on the structures of AR families. This became also apparent by the detection of traces of oxo-ARs with one and two double bonds (Table 2). GC/MS spectra of trimethylsilylated oxo-ARs did not differ essentially from those of isobaric ARs without an oxygen, irrespective of the degree of saturation (e.g. AR21:0 oxo AR22:0, AR21:1 oxo AR22:1) (Fig. 5). The differentiation between unsaturated oxo-ARs and isobaric conventional ARs was possible due to the accelerated CCC elution of the oxo-ARs. Again, it was likely that unsaturated oxo-ARs were formed by $\beta$-oxidation. Verification of the oxo-group in $\beta$ position can be determined by analysis of free [7] or acetylated oxo-ARs. Free $\beta$-oxo-ARs show the McLafferty ion at $m / z, 166$ which is formed by transfer of one $\mathrm{H}$ atom on $\mathrm{C} 5$ in the alkyl chain (in $\gamma$-position of the keto group) onto the oxygen of the carbonyl moiety followed by cleavage between $\mathrm{C} 3$ and $\mathrm{C} 4$ in the alkyl chain (ESM Fig. S6a). This fragment ion was also observed in di-acetylated oxo-AR at $m / z, 166$ (additional removal of both acetyl groups) along with $\mathrm{m} / \mathrm{z} 208$ (additional removal of one acetyl group) (ESM Fig. S6b). In addition, $\alpha$-cleavage on the left hand side of the keto group with the charge remaining in the alkyl chain resulted in the diagnostic fragment ions which additionally indicated the alkyl length of the oxo-AR (e.g. free and acetylated AR21:0 oxo produced $m / z 295$ (ESM Fig. S6). Di-fold acetylation shifted $\mathrm{M}^{+}$of the free AR21:0 oxo $(m / z$ 418) to $m / z 502$ (ESM Fig. S6). However, GC/MS spectra 
of acetylated oxo-ARs also featured $\left([\mathrm{M}-84]^{+}\right)$and $\mathrm{m} / \mathrm{z}, 460$ $\left([\mathrm{M}-42]^{+}\right)$which corresponded with neutral loss of two and one acetyl group(s), respectively (ESM Fig. S6).

Again, the connection between conventional and $\beta$ oxidized unsaturated ARs was obvious: three monounsaturated oxo-ARs and one diunsaturated oxo-AR isomer were detected. In agreement with that, Suzuki reported cis-configured double bonds in $n-5-, n-7-$ and $n$-9-positions for ARn: 1 oxo and in $n$-6- and n-9-position in ARn:2 oxo [10] (Table 2). DMDS adducts of ARn:1 oxo confirmed these positions by means of the $\mathrm{m} / \mathrm{z}$ series including the tail of the side chain at $\mathrm{m} /$

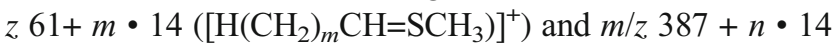
$\left(\left[\mathrm{CH}_{3} \mathrm{~S}=\mathrm{CH}\left(\mathrm{CH}_{2}\right)_{n} \mathrm{COC}_{6} \mathrm{H}_{2} \mathrm{SCH}_{3}\left(\mathrm{OSi}_{2}\left(\mathrm{CH}_{3}\right)_{3}\right)_{2}\right]^{+}\right)$in DMDS adduct 1 for fragment ions including the head group (TMS resorcinol ring).

$\mathrm{CCC}$ fractionation and subsequent GC/MS analysis verified the presence of the known oxo-ARs in rye (i.e. AR19:0 oxo, AR21:0 oxo, AR23:0 oxo, AR25:0 oxo plus three AR21:1 oxo and three AR23:1 oxo isomers) along with three AR19:1 oxo isomers and AR17:0 oxo which were described for the first time in rye (Table 2). All four oxo-ARs were detected in $\mathrm{CCC}$ fractions 5 and 6, i.e. the first fractions containing ARs (Fig. 4). Likewise, the proposed ECL of conventional ARs was also valid for oxo-ARs (Table 2). In support of this finding, the diunsaturated AR21:2 oxo was also detected in CCC fraction 6 (Fig. 4), while AR23:2 oxo, AR21:1 oxo and AR19:0 oxo were detected in CCC fraction 8 (Table 2).

\section{Methylated alkylresorcinols with saturated alkyl chains}

Several CCC fractions featured two saturated AR isomers (the same molecular ion). For instance, the classic AR22:0 (EV 96.6-129.2\%) was accompanied with an "AR22:0" isomer showing an EV of 99.6-126.3\%. The GC retention time of the second "AR22:0" isomer was shorter than the one of AR22:0 but GC/MS spectra were virtually identical except that the base peak of the "AR22:0" isomer was shifted by $14 \mathrm{u}$ to higher mass ( $m / z 282$ instead of $m / z$ 268) (Fig. 5a, e). Since the base peak is formed via phenyl cleavage, stabilized by loss of one $\mathrm{H}$ atom, the additional " $-\mathrm{CH}_{2}-$ " moiety must be either on the phenyl ring or in $\alpha$-position of the alkyl chain. Such ARs were not reported before in rye. However, ARs with a further methyl group on the resorcinol ring were detected before in quinoa (mAR17:0-mAR26:0 and mAR23:1) and wheat leaf cuticle wax (odd-numbered mAR19:0-mAR27:0) [30, 43]. NMR analysis allowed to assign the methyl group to 2position on the resorcinol backbone (i.e. between the two hydroxyl groups) [30]. Hence, it was most likely that the new ARs in rye also bore a 2-methyl substituent. Characteristic GC retention times and the diagnostic base peak at $\mathrm{m} / \mathrm{z} 282$ (see above and [30]) allowed to detect traces of five odd-chained mARs in the rye sample, namely mAR15:0-mAR23:0 (Table 2). mARs eluted together with the corresponding saturated $\mathrm{AR}$ isomer into the same CCC fractions, e.g. AR18:0 with mAR17:0 (Fig. 4, Table 2). Plots of $\log t_{\mathrm{R}}$ against the carbon number in the alkyl side chain resulted in straight lines for mARs as well as the abovementioned saturated ARs and oxo-ARs (Fig. 7b). Again, these plots proved to be conducive to distinguishing members of different substance classes with similar GC/MS data (Fig. 7b). Extrapolation of the mARs to isobaric saturated ones (exemplarily shown in Fig. 7b for AR20:0 and mAR19:0) showed the shorter GC retention times of mARs. Accordingly, GC mARs eluted between the corresponding ARs with the same chain length on the one side and isomeric ARs, for instance AR17:0 < mAR17:0 < AR18:0.

\section{Concluding remarks}

The presented method of combining CCC fractionation with offline GC/MS-SIM measurements strongly increased the number of detectable ARs. While GC/MS in full scan mode allowed the detection of eleven ARs, GC/MS-SIM enabled the detection of 29 ARs and CCC in combination with GC/MS-SIM allowed to detect 74 ARs in the rye sample. On the one hand, this approach helped to detect especially low abundant ARs. On the other hand, the orthogonal separation characteristics and especially the preparative nature of CCC made it possible to study uncommon ARs in CCC fractions by alternative methods such as DMDS adducts or acetylation. The use of a fraction collector and automated evaporator simplified the work load. However, the method is less suited for routine work as (here:) 80 fractions were analysed for one sample. In this context, other methods like LC/ MS(MS) are more suited. Yet, the high diversity of ARs as determined in this study had not been reached before. In addition, the high sample load in CCC along with sample fractionation was crucial for the subsequent structure determination including derivatisation steps (e.g. by formation of DMDS adducts). This approach enabled the detection of several novel ARs in rye including odd-chained methylated ARs, even-numbered monounsaturated ARs, triunsaturated AR and saturated oxo-AR. The potential of this established method can now be used for profiling other matrices. In particular, the comparison of cereal species with each other, the search for further unknown ARs and the targeted isolation of individual ARs by CCC are potential areas of this methodology.

Acknowledgments We are grateful to an anonymous reviewer of this manuscript for pointing us to the implementation of equation 1 .

Funding Open Access funding enabled and organized by Projekt DEAL.

\section{Compliance with ethical standards}

Conflict of interest The authors declare that they have no conflict of interest. 
Open Access This article is licensed under a Creative Commons Attribution 4.0 International License, which permits use, sharing, adaptation, distribution and reproduction in any medium or format, as long as you give appropriate credit to the original author(s) and the source, provide a link to the Creative Commons licence, and indicate if changes were made. The images or other third party material in this article are included in the article's Creative Commons licence, unless indicated otherwise in a credit line to the material. If material is not included in the article's Creative Commons licence and your intended use is not permitted by statutory regulation or exceeds the permitted use, you will need to obtain permission directly from the copyright holder. To view a copy of this licence, visit http://creativecommons.org/licenses/by/4.0/.

\section{References}

1. Ross AB, Shepherd MJ, Schüpphaus M, Sinclair V, Alfaro B, Kamal-Eldin A, et al. Alkylresorcinols in cereals and cereal products. J Agric Food Chem. 2003;51:4111-8.

2. Kamal-Eldin A, Pouru A, Eliasson C, Åman P. Alkylresorcinols as antioxidants: hydrogen donation and peroxyl radical-scavenging effects. J Sci Food Agric. 2001;81:353-6.

3. Kozubek A, Tyman JHP. Resorcinolic lipids, the natural nonisoprenoid phenolic amphiphiles and their biological activity. Chem Rev.1999;99:1-26.

4. Landberg R, Marklund M, Kamal-Eldin A, Åman P. An update on alkylresorcinols - occurrence, bioavailability, bioactivity and utility as biomarkers. J Funct Foods. 2014;7:77-89.

5. Thuścik F. Localization of the alkylresorcinols in rye and wheat caryopses. Acta Soc Bot Pol. 1978;47:211-8.

6. Zimmermann BF, Patzke H, Schieber A. Separation of alk(en)ylresorcinols from rye bran with saturated, monoenoic, dienoic, trienoic and hydroxylated monoenoic side chains using an octyl phase in ultra-high performance liquid chromatography and their differentiation by tandem mass spectrometry. J Chromatogr A. 2017;1506:65-72.

7. Seitz LM. Identification of 5-(2-oxoalkyl)resorcinols and 5-(2oxoalkenyl)resorcinols in wheat and rye grains. J Agric Food Chem. 1992;40:1541-6.

8. Ross AB, Kamal-Eldin A, Jung C, Shepherd MJ, Åman P. Gas chromatographic analysis of alkylresorcinols in rye (Secale cereale L) grains. J Sci Food Agric. 2001;81:1405-11.

9. Kozubek A, Tyman JHP. Cereal grain resorcinolic lipids: mono and dienoic homologues are present in rye grains. Chem Phys Lipids. 1995;78:29-35.

10. Suzuki Y, Esumi Y, Yamaguchi I. Structures of 5-alkylresorcinolrelated analogues in rye. Phytochemistry. 1999;52:281-9.

11. Ito Y. Golden rules and pitfalls in selecting optimum conditions for high-speed counter-current chromatography. J Chromatogr A. 2005; 1065:145-68.

12. Friesen JB, McAlpine JB, Chen S-N, Pauli GF. Countercurrent separation of natural products: an update. J Nat Prod. 2015;78: 1765-96.

13. Marchal L, Intes O, Foucault A, Legrand J, Nuzillard J-M, Renault $\mathrm{J}-\mathrm{H}$. Rational improvement of centrifugal partition chromatographic settings for the production of 5-n-alkylresorcinols from wheat bran lipid extract. J Chromatogr A. 2003;1005:51-62.

14. Intes $\mathrm{O}$, Renault JH, Thepenier P, Zeches-Hanrot M, Nuzillard JM, Laignel B, Bertho JN, Baynast R. de in: Counter-current chromatography Symposium (CCC 2000), Uxbridge, 10-14 September, 2000
15. Friesen JB, Pauli GF. G.U.E.S.S. - a generally useful estimate of solvent systems for CCC. J Liq Chromatogr Relat Technol. 2005;28:2777-806.

16. Hammann S, Tillmann U, Schröder M, Vetter W. Profiling the fatty acids from a strain of the microalgae Alexandrium tamarense by means of high-speed counter-current chromatography and gas chromatography coupled with mass spectrometry. J Chromatogr A. 2013;1312:93-103.

17. Schröder M, Vetter W. Detection of 430 fatty acid methyl esters from a transesterified butter sample. J Am Oil Chem Soc. 2013;90: 771-90.

18. Hammann S, Kröpfl A, Vetter W. More than 170 polyunsaturated tocopherol-related compounds in a vitamin E capsule: countercurrent chromatographic enrichment, gas chromatography/mass spectrometry analysis and preliminary identification of the potential artefacts. J Chromatogr A. 2016;1476:77-87.

19. Knödler M, Conrad J, Wenzig EM, Bauer R, Lacorn M, Beifuss U, et al. Anti-inflammatory 5-(11'Z-heptadecenyl)- and 5-(8'Z,11'Zheptadecadienyl)-resorcinols from mango (Mangifera indica L.) peels. Phytochemistry. 2008;69:988-93.

20. Buser HR, Arn H, Guerin P, Rauscher S. Determination of double bond position in mono-unsaturated acetates by mass spectrometry of dimethyl disulfide adducts. Anal Chem. 1983;55:818-22.

21. Wendlinger $\mathrm{C}$, Vetter $\mathrm{W}$. High concentrations of furan fatty acids in organic butter samples from the German market. J Agric Food Chem. 2014;62:8740-4.

22. Zarnowski R, Suzuki Y. Expedient Soxhlet extraction of resorcinolic lipids from wheat grains. J Food Compos Anal. 2004;17:649-63.

23. Weichbrodt M, Vetter W, Luckas B. Microwave-assisted extraction and accelerated solvent extraction with ethyl acetate-cyclohexane before determination of organochlorines in fish tissue by gas chromatography with electron-capture detection. J AOAC Int. 2000;83: $1334-44$.

24. Hammann S, Englert M, Müller M, Vetter W. Accelerated separation of GC-amenable lipid classes in plant oils by countercurrent chromatography in the co-current mode. Anal Bioanal Chem. 2015;407:9019-28.

25. Hammann S, Wendlinger C, Vetter W. Analysis of intact cholesteryl esters of furan fatty acids in cod liver. Lipids. 2015;50:611-20.

26. Schröder M, Vetter W. High-speed counter-current chromatographic separation of phytosterols. Anal Bioanal Chem. 2011;400:361523.

27. Ross AB, Åman P, Andersson R, Kamal-Eldin A. Chromatographic analysis of alkylresorcinols and their metabolites. J Chromatogr A. 2004;1054:157-64.

28. Mullin WJ, Collins FW. Purification and identification of alk(en)ylresorcinols. J Food Compos Anal. 1991;4:270-5.

29. Occolowitz JL. Mass spectrometry of naturally occurring alkenyl phenols and their derivatives. Anal Chem. 1964;36:2177-81.

30. Ross AB, Svelander C, Karlsson G, Savolainen OI. Identification and quantification of even and odd chained 5-n alkylresorcinols, branched chain-alkylresorcinols and methylalkylresorcinols in quinoa (Chenopodium quinoa). Food Chem. 2017;220:344-51.

31. Ross AB, Kamal-Eldin A, Åman P. Dietary alkylresorcinols: absorption, bioactivities, and possible use as biomarkers of wholegrain wheat- and rye-rich foods. Nutr Rev. 2004;62:81-95.

32. Englert $\mathrm{M}$, Hammann $\mathrm{S}$, Vetter $\mathrm{W}$. Isolation of $\beta$-carotene, $\alpha$ carotene and lutein from carrots by countercurrent chromatography with the solvent system modifier benzotrifluoride. J Chromatogr A. 2015;1388:119-25.

33. Gallistl C, Vetter W. Synthesis, liquid chromatographic fractionation and partial characterization of polybrominated dibenzofuran congeners. J Chromatogr A. 2016;1442:62-72. 
34. Friesen JB, Pauli GF. Rational development of solvent system families in counter-current chromatography. J Chromatogr A. 2007;1151:51-9.

35. Berthod A, Bully M. High-speed countercurrent chromatography used for alkylbenzene liquid-liquid partition coefficient determination. Anal Chem. 1991;63:2508-12.

36. de Folter J, Sutherland IA. Probabilistic model for immiscible separations and extractions (ProMISE). J Chromatogr A. 2011;1218: 6009-14.

37. Englert M, Brown L, Vetter W. Heart-cut two-dimensional countercurrent chromatography with a single instrument. Anal Chem. 2015;87:10172-7.

38. Bousquet O, Le Goffic F. Counter-current chromatographic separation of polyunsaturated fatty acids. J Chromatogr A. 1995;704: 211-6.

39. Englert M, Vetter W. Overcoming the equivalent-chain-length rule with $\mathrm{pH}$-zone-refining countercurrent chromatography for the preparative separation of fatty acids. Anal Bioanal Chem. 2015;407: 5503-11.
40. Vetter W, Müller M, Sommer K, Schröder M, Hammann S. Development of equivalent chain length (ECL) rules for lipid compounds. J Chromatogr A. 2019;1599:187-95.

41. Suzuki Y, Esumi Y, Uramoto M, Kono Y, Sakurai A. Structural analyses of carbon chains in 5-alk(en)ylresorcinols of rye and wheat whole flour by tandem mass spectrometry. Biosci Biotechnol Biochem. 1997;61:480-6.

42. Carballeira NM, Shalabi F, Cruz C. Thietane, tetrahydrothiophene and tetrahydrothiopyran formation in reaction of methyleneinterrupted dienoates with dimethyl disulfide. Tetrahedron Lett. 1994;35:5575-8.

43. Adamski NM, Bush MS, Simmonds J, Turner AS, Mugford SG, Jones A, et al. The inhibitor of wax 1 locus (Iw1) prevents formation of $\beta$ - and $\mathrm{OH}-\beta$-diketones in wheat cuticular waxes and maps to a sub-cM interval on chromosome arm 2BS. Plant J. 2013;74: 989-1002.

Publisher's note Springer Nature remains neutral with regard to jurisdictional claims in published maps and institutional affiliations. 